\title{
Flujo hipersónico sobre misiles
}

\section{Hipersonic flow over missiles}

\author{
Recibido: noviembre 20 de 2019 | Revisado: diciembre 12 de 2019 | Aceptado: enero 06 de 2020
}

Luis A. Arriola

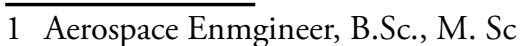
Facultad de Ingeniería y Arquitectura, Escuela Profesional de Ciencias Aeronáuticas

Universidad de San Martín de Porres, Lima Perú

larriolag@usmp.pe

\begin{abstract}
Resumen
Entre otras técnicas, las técnicas para resolver problemas de flujo sobre misiles hipersónicos modernos que están en el régimen de flujo hipersónico son las soluciones exactas. La primera solución exacta se basa en las relaciones de ondas de choque oblicuas y se mantiene para todos los números de Mach superiores a la unidad, supersónicos o hipersónicos, suponiendo gases perfectamente calóricos. El segundo método de solución exacta es el método de inclinación de superficie local basado en la teoría newtoniana. El tercer método de solución exacta es el método de pequeña perturbación hipersónica que se basa en los supuestos de que la pendiente de la superficie local del cuerpo en la dirección de la corriente es pequeña en todas partes en comparación con la unidad; las perturbaciones de velocidad son pequeñas en comparación con la velocidad de flujo libre, y la perturbación de presión es pequeña en comparación con la presión dinámica de flujo libre.
\end{abstract}

Palabras clave: hipersónico, onda de choque, numero mach, supersónico, gases calóricos, teoría newtoniana, presión dinámica

\begin{abstract}
Among others, the techniques to solve problems of the modern hypersonic missiles which are in the hypersonic flow regime are the exact solutions. The first exact solution is based on the oblique shock wave relations and hold for all Mach numbers greater than unity, supersonic or hypersonic flows assuming perfectly caloric gases. The second exact solution method, is the local surface inclination method based on Newtonian theory. The third exact solution method is the small hypersonic disturbance method which is based on the assumptions that the slope of the local surface of the body in the stream wise direction is everywhere small compared with unity; the velocity perturbations are small compared with the freestream velocity, and the pressure perturbation is small compared with the freestream dynamic pressure.
\end{abstract}

Key words: hypersonic, shock wave, Mach numbers, supersonic, caloric gases, Newtonian theory, dynamic pressure

(C) Los autores. Este artículo es publicado por la Revista Campus de la Facultad de Ingeniería y Arquitectura de la Universidad de San Martín de Porres. Este artículo se distribuye en los términos de la Licencia Creative Commons Atribución No-comercial - Compartir-Igual 4.0 Internacional (https://creativecommons.org/licenses/ CC-BY), que permite el uso no comercial, distribución y reproducción en cualquier medio siempre que la obra original sea debidamente citada. Para uso comercial contactar a: revistacampus@usmp.pe. 


\section{Introduction}

When the space shuttle enters the earth's atmosphere form near-earth orbit, it is flying at Mach 25. When the Apollo spacecraft returned from the moon, it entered the atmosphere at
Mach 36. Today, there are new concepts of space vehicles such as hypersonic missiles as shown in Figure 1 but which are based on the concept of the 1980s and experiments that took place in the 1959s and 1960s.

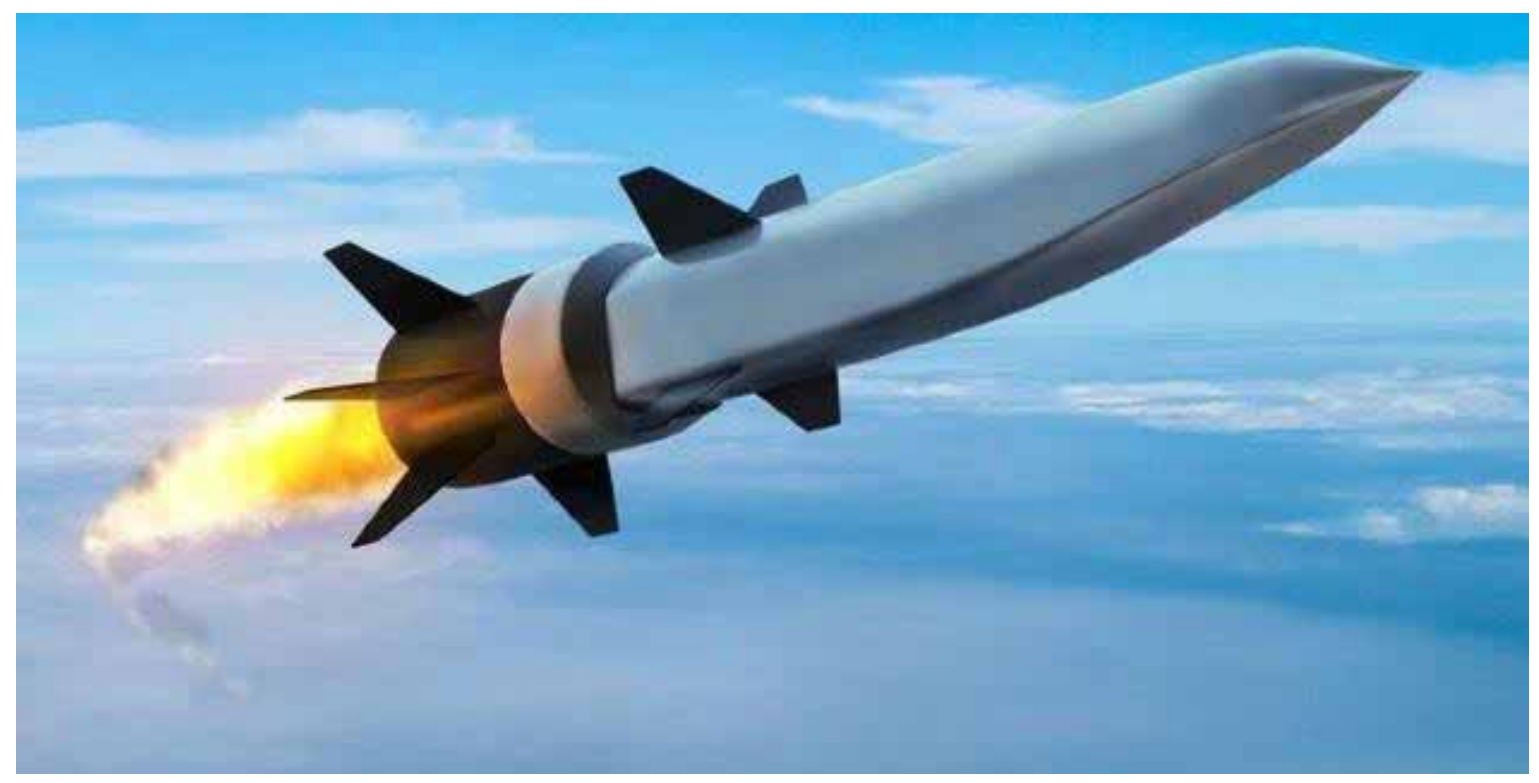

Figure 1. Hypersonic Missile

These high values of Mach numbers are associated with the extreme portion of high values of the flight spectrum which is referred as Hypersonic Flight. From the aerodynamic point of view, it is necessary to understand the principles and fundamentals in a flow whose velocity is extremely high as in the hypersonic range. This can happen just around space vehicles, as it is the case of hypersonic missiles of the present years and later 2020s.

\section{Discussion}

In spaceflight, and generally in highspeed flights it is common to refer to the Mach number as a measure of vehicle speed compared to the speed of sound. There is a conventional rule of thumb that defines hypersonic aerodynamics as those flows where the Mach number is greater than 5 as defined by Zucrow \& Hoffman (1976). However, this is no more than just a rule of thumb; when a flow is accelerated from Mach 4.99 to 5.01 , there is no "clash of thunder" and the flow does not "instantly turn from green to red". Rather, a hypersonic flow is better defined as that regime where certain physical flow phenomena become progressively more important as the Mach number is increased to higher values. Among the concepts and principles that arise in this type of hypersonic flow regime are the following according to Shapiro (1953).

\section{Thin Shock Layers}

Considering the theory of oblique shock waves that, for a given flow 
deflection angle, the density increase across the shock wave becomes progressively larger as the Mach number is increased. At higher density, the mass flow behind the shock wave can more easily "squeeze through" smaller areas. For a flow over a hypersonic body such as a missile, this means that the distance between the body and the shock wave can be small.

\section{Entropy Layer}

There are some options in forms of hypersonic vehicles. The sharp tip and the blunt nose tip. Unlike those with a sharp tip, in those with a blunt nose and hypersonic Mach numbers, a shock layer over the blunt nose is formed which is also very thin (compared to that with a sharp tip) and with a small separation distance in the nose called "detachment". Entropy is energy, and the entropy of the flow is increased through a shock wave, and thus, the stronger the shock wave, the larger the entropy increase. This layer which contains the energy, called entropy layer causes analytical problems when you want to perform standard boundary layer (boundary layer phenomena) calculations on the surface of the vehicle.

\section{Viscous Interaction}

A high-speed hypersonic flow contains a large amount of kinetic energy. When this flow is decelerated by the viscous effects within the boundary layer, the lost kinetic energy is transformed (in part) into internal energy of the gas, so call viscous dissipation. Thus, the temperature is increased within the boundary layer and heat can be transferred to the vehicle if protective measures of aerodynamic, thermal and structural design are not taken in consideration.

\section{High Temperature Flows}

Extreme viscous dissipation that occurs within hypersonic boundary layers can create very high temperatures. So high, as to energize or stimulate vibrational energy internally between molecules, and cause dissociation and even more, ionization within the gas. If the surface of the hypersonic vehicle is protected by an ablative heat shield, the ablation products are also present in the boundary layer, leading to complex chemical reactions of hydrocarbons. In this way, we can see that the surface of a hypersonic vehicle can be affected by a boundary layer reacting chemically.

Among the techniques to solve this type of high-speed flows are the exact solutions. The first exact solution is based on the oblique shock wave relations and hold for all Mach numbers greater than unity, supersonic or hypersonic flows assuming perfectly caloric gases. However, some interesting approximations and simplified forms of this type of oblique shock wave relations are obtained at the limit of high Mach number values. There is a second exact solution that is based on the local surface inclination method which is a method based on Newtonian theory; and a third exact solution method is based on the relations of small hypersonic disturbances. The pressure distribution $\mathrm{Cp}$, is particularly important since it is a measure of how much can stand the vehicle under pressure due to higher values of speed. For the first exact solution method, which is based on the oblique shock wave relations 
and occurring in the hypersonic limit (Mach number $\rightarrow \infty$ ), the relation for the pressure distribution as defined by Anderson (2003) is the following: $\mathrm{Cp}=$ $(4 /(\gamma+1)) \sin ^{2} \beta$. Where $\gamma$ is a constant value of 1.4 for dry air, the Mach number is in the hypersonic limit, $\beta$ is the shock angle, and $\theta$ is the deflection angle where theta and $\beta$ are small as indicated in Figure 2.

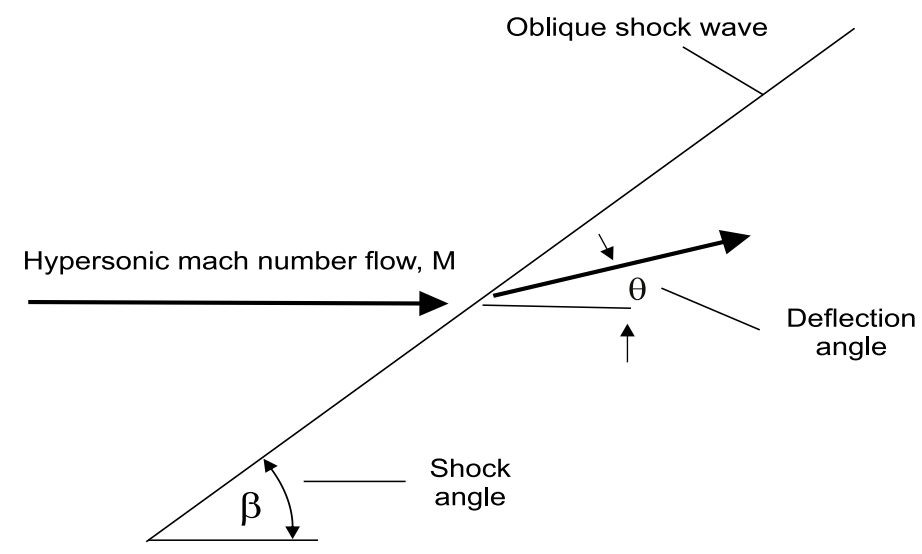

Figure 2. Oblique shock wave geometry

Then, according to Anderson, Jr. (2003), the relation between $\beta$ and $\theta$ for the hypersonic limit and under these small angles case is:

$$
\beta_{\bar{\theta}}=\frac{\gamma+1}{2}
$$

For the second exact solution method, which is the oldest and most widely used local surface inclination method based on Newtonian theory, the surface pressure distribution for hypersonic bodies is also defined by Anderson (2003) as: $\mathrm{Cp}=$ $2 \sin ^{2} \theta$.
In the Newtonian model of fluid flow, the particles in the free stream impact only on the frontal area of the body; they cannot curl around the body and impact on the back surface. Hence, for that portion of a body which is in the "shadow" of the incident flow, such as the shaded region sketched in Figure 2, no impact pressure is felt. Hence, over this shadow region it is consistent to assume that $\mathrm{p}=\mathrm{p} \infty$, where $\mathrm{p}$ is the pressure variation around the body and $\mathrm{p}_{\infty}$ is the free stream pressure, and therefore $\mathrm{Cp}=0$, as indicated in Figure 3 .

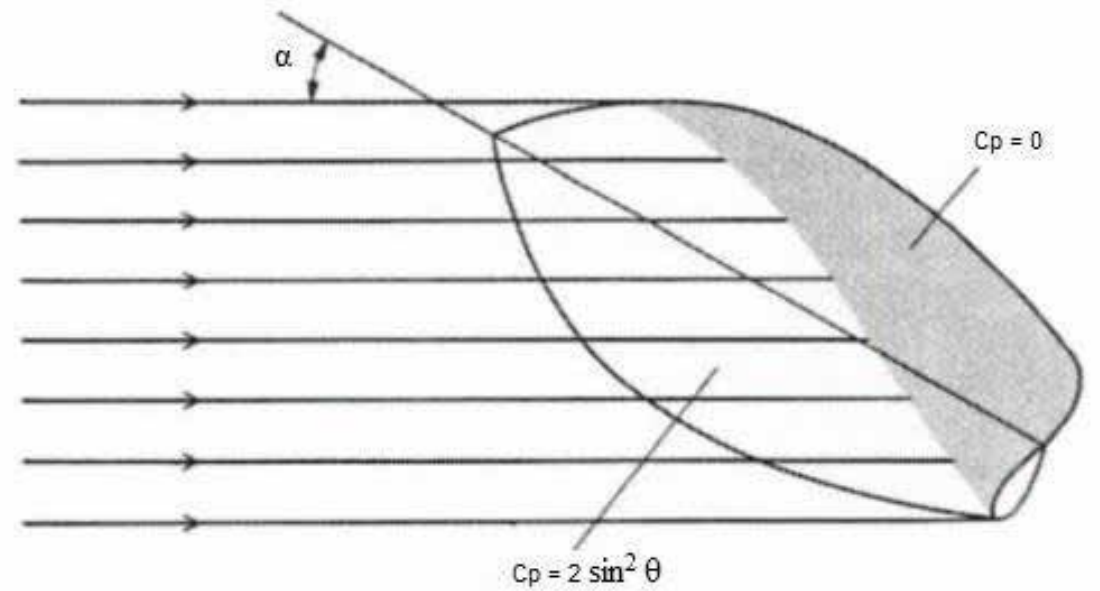

Figure 3. Shadow region on the leeward side of a body, from Newtonian theory 
Finally, the third and last exact solution method of small hypersonic disturbances is based on the assumptions that the slope of the local surface of the body in the stream wise direction is everywhere small compared with unity; the velocity perturbations are small compared with the freestream velocity, and the pressure perturbation is small compared with the freestream dynamic pressure. However, the "modern" hypersonic aerodynamics is characterized by applications of computational fluid dynamics (CFD) which is based on numerical methods. CFD had an impact due mainly to the lack of hypersonic ground test facilities for experimental studies, especially at the extreme ends of the spectrum where the Mach number greater than 20 and the stagnation temperatures are high enough to cause substantial chemical dissociation of the gas. In lieu of such high-performance facilities, the design of hypersonic vehicles such as the hypersonic missiles must rely heavily on the results of computational fluid dynamics.

\section{Conclusions}

It is important to understand the physical phenomenon in this type of high speed regime since a different behavior of the flow around the space vehicle occurs. This behavior of particles that we have described as dissociation of molecules and ionization of particles from the flow around the vehicle greatly affect the material over the entire surface of the vehicle. However, if the vehicle is not properly protected to withstand high temperatures and heat transfer and ions, then damage to the structure of the vehicle and its avionics is imminent. In general, it is the shape of the surface of the vehicle which is shaped in order to mitigate these effects of hypersonic flow as well as using protection such as the surface protective thermal shields. In order to shape the surface of the vehicle in question, any of the methods briefly described here can be applied.

\section{References}

Anderson, Jr. (2003). Modern Compressible Flow with Historical Perspective. NY: McGraw Hill Shapiro, A. (1953). The
Dynamics and Thermodynamics of Compressible Fluid Flow. N.Y Zucrow, M.\& Hoffman J. (1976). Gas Dynamics. New York: Wiley 
